\title{
An Analysis of the Changing Roles of Hotel Concierges
}

\author{
Howard Adler, Susan Gordon \\ Purdue University, Indiana, USA
}

\begin{abstract}
The focus of this research was to analyze how the role of the hotel concierge has changed with regard to the types of services offered and the volume and types of customer requests that concierges in the United States receive. Concierges in selected major cities were surveyed. Concierges felt that guests of today are more savvy and that technology helped them give better information and service. However, they felt that although guests have access to a great deal of information, most guests continue to rely on personal recommendations from concierges. Concierges also have new roles such as monitoring hotel websites or social media sites and are confronted with a great deal of new and changing information. Conclusions stem from the fact that although hotel companies have a great deal of technology available to them, the person service provided by concierges is still preferred by customers. The literature related to the use of concierge services is sparse and therefore, this paper was intended to provide a basis for future investigation. Implications related to maintaining a high level of guest were discussed.
\end{abstract}

Keywords: hotels, concierge, hotel technology, guest service

\section{Introduction}

The concept of the modern concierge is said to have emerged in the mid-1600 from the French term "Comte Des Cierges", which means "the keeper of the candles" who tended to visiting nobles in castles of the medieval royalty. Later, the concierge was a high official appointed by the king to keep order and to keep the keys to the palace (New York City Association of Hotel Concierges). During the 1800s, the growth of world travel created a need for upscale hotels and travel assistance. The role of the concierge has grown to where they now are employed in apartment buildings, the corporate world, and all first-class hotels.

Concierge services are the key to success of full-service hotels and a way to differentiate a hotel from its competitors. Hotel companies have embraced technology as a way to enhance services. Currently, very little research exists on the changing roles of the modern concierge. Therefore, the purpose of the present research was to analyze how the role of concierges has changed. Specific research objectives are as follows:

(1) Analyzing how the role of the concierge has changed in the type of requests and the amount of requests;

(2) Measuring how technology has affected the delivery of guest services by the concierge;

(3) Exploring concierge perceptions with regard to the tools which they use to provide guest service.

Howard Adler, Ed.D., C.B. Smith Professor of Hotel Management, School of Hospitality and Tourism Management, Purdue University.

Susan Gordon, research assistant, Ph.D. candidate, School of Hospitality and Tourism Management, Purdue University.

Correspondence concerning this article should be addressed to Howard Adler, School of Hospitality and Tourism Management, Purdue University, Marriott Hall, West Lafayette, Indiana 47907, USA. Tel.: 765494 5998. Email: adlerh@purdue.edu. 
The significance of this research lies in the competitive nature of four- and five-star hotels. These types of hotels strongly rely on service as a way to differentiate their hotels from their competitors. The concierge is a key player in the delivery of service to hotel guests and therefore, it is important for hotels to understand the needs of guests and how guests are utilizing the services of this position. Hotel managers can use the findings to make improvements to the types and degree of concierge services and, therefore, ensure that they continue to exceed guest expectations.

\section{Literature Review}

\section{Changes and Effects on Guest Service}

Frequently, guests feel that their main experiences with companies are the exchanges they have with frontline employees (Bitner, Brown, \& Meuter, 2000). The concierges of four- and five-star hotels are often the ones providing this service experience. A hotel concierge fulfills a variety of guest requests ranging from giving directions to making dinner reservations, to obtaining tickets to sold-out shows, and to providing personal shopping. In essence, the concierge must meet any guest requests regardless of how unusual the request is. "Synonymous with extraordinary service, a concierge is expected to achieve the impossible and fulfill any request with efficiency, speed, discretion, and creativity” (Stiel, 2010 ${ }^{1}$ ). To achieve the seemingly impossible, the concierge relies on personal networks of local businesses and service providers, which now include utilizing the Internet and other computer applications.

Technology is impacting service encounters across all types of industries and changing the nature of the traditional "high-touch, low-tech" dimension of service encounters. A concierge must read guests correctly, because they are often asking the concierge to make a decision for them and we do not want to get it wrong (Madden, 2010). Furthermore, in some cases, technology is even replacing these personal service encounters, such as bank ATMs or online ticketing for airlines (Bitner et al., 2000). These technological implementations can positively or negatively affect the customers' perception of service quality. Service quality has been defined as a result of the perceived difference between expected service and the service received (Parasuraman, Zeithaml, \& Berry, 1985). A study of M. Joseph, McClure, and J. Joseph (1999) found that respondents did not feel that electronic banking services performed at their level of expectations, but nevertheless $52.9 \%$ of them stated that they were satisfied with the service. Meuter, Ostrom, Roundtree, and Bitner (2000) examined customer satisfaction with service encounters received via self-service technology (SST) across various industries. The study found that $29 \%$ of the service encounters were satisfying due to the technology, but $34 \%$ of the encounters were dissatisfying due to the technology. Furthermore, the study found that when the service encounter went poorly, respondents were more likely to blame the technology over themselves even though they, rather than a company employee, were producing the service. High-tech concierge services represent one way in which hotels can differentiate themselves to add services. They usually rank among the highest for guest satisfaction and help to achieve higher rates. Even mid-priced hotels have gone in a digital direction in terms of concierge services by offering 55-inch touch screens in hotel lobbies, such as Courtyard by Marriott. Hyatt brands also have Twitter-based services in all of its hotels (Levere, 2011).

Very often, hotel managers have mixed feelings about technology and guest service. They want to take advantage of technology, but they at the same time also do not want to lose face-to-face interactions with their

${ }^{1}$ Retrieved from http://www.thankyouverymuchinc.com. 
guests. Concierges still feel that personal interaction is the key to being able to perform their jobs. According to Arnaldo (2011), one concierge stated that working with guests on a one-to-one basis is gratifying, but the computer can take the concierge away from giving that personalized service. Bitner et al. (2000) cautioned managers against relying too much on technology stating that "some consumers may prefer the social aspects of interacting closely and developing relationships with service providers or other customers during service encounters" (p. 147). Another example of how the position of concierge is changing regards Facebook. In many hotels, the concierge is in charge of managing requests that come over the hotels' Facebook page. Having an effective Facebook page can ultimately lure guests to the hotel. The Facebook page can become a virtual concierge when it provides relevant travel information and provides guests with the information that they need (Nayer, 2011).

In terms of integrating technology with their jobs, not only do concierges utilize the Internet to access websites, but they are also members of certain relevant sites and receive emails about new restaurant or show openings, upcoming special events, or newsletters with pertinent information which previously were distributed by word of mouth or postal mails (personal communication, December 6, 2010). Furthermore, hotels view online concierge service as a way to build relationships with guests before they arrive at the hotel. This allows hotels to begin to fulfill guest requests prior to arrival and alleviates guests from standing in line at the concierge desk to make requests after check-in (McMullen, 2006). Hotels have found that guest use is high and just like in-person requests, requests range from simple to complicated (McMullen, 2006). Upon booking a reservation, the Pod Hotel in New York City assigns its guests a username and password to access the hotel's social network site called PodCulture. Through this site, guests can interact with each other as well as the hotel staff, and the site has a virtual concierge through which the hotel concierge answers questions from guests (Kasavana, Nusair, \& Teodosic, 2010).

Replacing employees with kiosks might work in airports, but in hotels, guests continue to expect to be able to speak with a person and maintaining a concierge service is one way a hotel can distinguish itself (Craig, 2010). One study found that in a hotel setting, personal service still contributes more to guest satisfaction than SST (Beatson, Coote, \& Rudd, 2006). Guests may appreciate the technology provided by the hotel and feel satisfied using it, but hotels should not assume that technology will improve performance (Ham, Kim, \& Jeong, 2005).

\section{Guest Service Technology in the Hotel Industry}

Hotels have been steadily increasing their investments in technology year after year, because it has been proven that information technology (IT) investments lead to increased productivity, cost reduction, and value added to products and services for guests (Bilgihan, Okumus, Nusair, \& Kwun, 2011). Limited service hotels (i.e., budget, economy) are likely to invest in IT to gain operating efficiency as compared to those hotels in the upscale and luxury markets that pursue IT that improves service delivery to guests (Bilgihan et al., 2011).

Choice Hotels International has an app that allows guests to book rooms and even employ the smart phone GPS to assist them in locating the nearest properties. Within the application, each individual property has its own page that shows room rates, pictures, and amenities (Kirby, 2009). Omni Hotels initiated its technology by offering an application that accesses the mobile site and includes links to the company's Twitter and Facebook pages as well as a login for its guest loyalty program page. "Future software updates may include mobile checkout functionality, virtual concierge information, and possibly a page that mimics the brand's pre-arrival 
e-mails” (Kirby, 2009, p. 43). Omni has found that its conversion rate on mobile bookings as compared to online bookings is $150 \%$ higher (Lombardi, 2010). Hilton now offers mobile check-in that allows a guest to enter the hotel and go to the room without even stopping at the front desk. In addition, guests can order room service or other amenities from the road and have it waiting for them upon arrival at the hotel (Lombardi, 2010). "Omni is launching an online concierge service that will allow guests to order whatever amenities they'd like once they're on property, with their mobile devices, so even if they're at a meeting, they can order it from anywhere" (Lombardi, 2010, p. 52).

Guests are increasingly using technology to assist with their travel needs. A recent survey reported that $64 \%$ of guests say that they use social media to make their plans with the amount jumping to $76 \%$ for those in the 25-34 age range (De Lollis, 2010). In addition, guests are using smart phones to find local attractions and venues via GPS, so companies are now taking advantage of location-based messaging to reach potential customers (Lombardi, 2010). A survey conducted by PhoCusWright found that $67 \%$ of travelers used a mobile device to locate local services (Craig, 2010).

Traditional concierge services can be supplemented by advances in guest services via technology which is offered to guests. The Millennium Broadway in New York City offers laptops for rent to its guests and even offers to have the hotel staff set it up to connect to the guests' corporate networks (Lombardi, 2010). The Ritz Carlton in Chicago has instituted a "Compcierge" position in which an employee assists guests with technology-related problems (Yeh, Leong, Blecher, \& Lai, 2005). Many hotels are employing SST so that guests can utilize products and services without assistance from the service provider (Schrier, Erdem, \& Brewer, 2010). The Hotel Duval in Tallahassee, Florida has in-room kiosks that allow guests to place room service orders, book spa treatments, make reservations, and more. The hotel has found in comparison to orders placed with hotel staff, this device has decreased order error and increased average spend by about $60 \%$ (Crowell, 2010). In addition, the hotel benefits from data collection, as it can monitor data such as volume and spend, but it can also use the kiosk to make recommendations to guests (Crowell, 2010). The Westin Santa Clara utilizes Sony's Contact-ME for remote video conferencing between concierges and guests whether the concierge is at home and the guest is at the hotel or the guest is at home and the concierge is at the hotel (Arnaldo, 2011).

The distinct advantage that hotel concierges have over any technology is their humanness. They have the power of insight and to be discerning and intuitive. The guest might have to consult many sites to get the proper information while they can often get it all through one concierge. An effective concierge can be a driver of repeat business and positive word of mouth, which ultimately means that mobile users will use technology to speak highly of the hotel (Noel, 2012).

\section{Unique Changes to Concierges}

Hotels are constantly coming up with new and unique ideas for guest services and frequently, concierges are involved in those changes. One example is "specialty concierges". These specialty services might only appeal to a limited number of guests; however, to that guest, it might make a major difference in customer satisfaction. Examples of this include a recovery concierge at the Ritz Carlton, New Orleans who deals with hangovers, a soap concierge Viceroy Hotel in Playa Del Carmen who introduces guests to various varieties of soap, a romance concierge at the Rondezvous Hotel in St Lucia to a running concierge with Westin Hotels and Resorts. The services extend to butler services which are often aligned with the concierge department (Hill, 
2013). There are those who feel that the modern concierge is in danger of dying out. Many hotel companies are attempting to refresh the role of the concierge. Renaissance Hotels by Marriott has come up with a navigator concept that puts staff from various departments in positions of giving guest recommendations to replace the regular concierge position. The Andaz brand by Hyatt has come up with the concept of Andaz host which is a combination of doorman, concierge, bell attendant, and front desk agent (You, 2012).

To be a great concierge, the position of concierge requires certain qualities. While these might be common qualities, they are difficult to find in one person and include empathy, approachability, connecting with people, discretion, integrity, patience, tolerance, sincerity, generosity, diplomacy, curiosity, accountability, passion, humility, resourcefulness, perseverance, and a strong memory (Tanguy, 2013). Dealing with human beings requires that the concierge sometimes deal with outrageous requests, such as private meetings with celebrities or politicians to bringing a beach to a hotel nowhere near a beach. Not every outrageous request can be met especially if it compromises employee or guest safety (Rogers, 2009).

\section{Methodology}

Hotel concierges are visible and interact with guests on a one-on-one basis. Because of this, they are able to give the best perspective as to changes in guest requests and how their jobs have evolved and how their roles have changed. For the purpose of this exploratory study, concierges in selected cities across the United States were surveyed regarding their perception of how their roles and jobs have changed.

\section{Research Participants}

A review was conducted of those cities which had concierge associations. The existence of such an association indicated that there were a large enough number of hotel concierges in those cities. A list of fourand five-star hotels in New York, Boston, Chicago, Los Angeles, Las Vegas, Philadelphia, Orlando, Atlanta, and San Francisco was compiled. The hotels were called to ascertain the number of concierges who worked in those hotels, and it was determined that the number was 350. An email was sent to the director of human resource in those hotels who was asked if they could forward the email explaining the research along with a link to the survey.

\section{Survey Instrument}

Questions were derived from a review of the related literature and semi-structured interviews with six concierges. The survey was conducted using Qualtrics and was distributed to concierges via an email link that was provided to them. Confidentiality of the respondents was assured and no personal information could be identified. The survey included an electronic letter that advised the participants of the confidentiality and anonymity of their responses and the importance of the research. The letter also provided the participants with the researchers' names and contact information.

The survey consisted of three parts. The first part consisted of questions to gather demographic information, such as the city in which the concierges work, how long they have worked in the hospitality industry, how long they have been a concierge, and the length of employment as a concierge at their current hotel. In the second section, concierges were asked to rate their level of agreement with statements designed to assess the concierges' perceptions of how their positions and roles have changed and how it has impacted their ability to provide guest service. A sample of these questions includes: (1) I have the training I need to do my job; (2) I have the technology I need to do my job; (3) Guests use concierge services for different requests than 
they used to; (4) Guest requests are more time-consuming than they used to be; (5) Guests want more personal recommendations than before; and (6) I use my personal smart phone a great deal to meet guest requests. These questions were answered using a Likert scale ranging from 1 to 5, with 1 as strongly disagree, 2 as disagree, 3 as neither disagree nor agree, 4 as agree, and 5 as strongly agree. Part three of the survey consisted of an open-ended qualitative question that involved perceptions of concierges in the area of guest requests and technology.

\section{Analysis and Results}

\section{Sample Profile}

A profile of the respondents is provided in Table 1. From the 181 responses, 164 provided complete information to both the demographic questions and perception questions. The majority of the respondents (82\%) were employed by hotels that have 201 rooms or more with $85 \%$ of the respondents working in hotels that were rated as four or five stars. The majority of respondents (67\%) had college degrees, and only $12 \%$ of those held a degree in hospitality and tourism compared with $20 \%$ who held one in business.

Table 1

Concierge Demographics

\begin{tabular}{lcc}
\hline & Sample profile & \\
\hline Number of rooms & Frequency & Percent (\%) \\
\hline Less than 100 & 10 & 6 \\
$101-200$ & 19 & 21 \\
$201-300$ & 35 & 21 \\
$301-400$ & 34 & 40 \\
More than 400 & 66 & Percent (\%) \\
\hline Number of stars of hotel & Frequency & 2 \\
2 stars & 3 & 13 \\
3 stars & 22 & 67 \\
4 stars & 110 & 18 \\
5 stars & 29 & Percent (\%) \\
\hline Have a college degree & Frequency & 67 \\
\hline Yes & 110 & 33 \\
No & 54 & Percent (\%) \\
\hline Degree area & Frequency & 12 \\
\hline Hospitality and tourism & 20 & 20 \\
Business & 32 & 68 \\
Other & 112 & \\
\hline
\end{tabular}

Concierges were asked whether or not the parent company had a smart phone application. As can be seen from Table 2, 47\% said yes and 53\% answered no. This is compared to only 33\% of individual hotels having their own applications. In terms of types of social media accounts maintained by individual hotels, the majority has Facebook pages (77\%) and Twitter accounts (62\%). This is consistent with companies overall in the United States, as $80 \%$ of companies use Facebook, but higher than the overall use of Twitter in the United States, as approximately only $45 \%$ have a Twitter account (InSites Consulting, 2012).

Of the 164 responses, 65 (43\%) provided additional comments on their hotel's use of social media. While few concierges reported being in charge of updating the social media sites, those who do help update them 
range from updating them on a daily basis to simply answering guest questions to writing a blog for the hotel. One concierge is an administrator for the hotel's site and works closely with the hotel's public relation (PR) director. Another concierge mentioned that all concierges at the hotel are encouraged to update the hotel's Twitter account on a daily basis and employees in the food \& beverage department are responsible for updating the information about the restaurant. This was also true of someone else who said that he updates the information. Another concierge reported being in charge of answering guest questions and comments on the social media sites. One concierge even writes a monthly blog that appears as part of the hotel's sales department's website. Intercontinental Hotels Group has a concierge website where guests can get information about the city and be in contact with their concierge desk before their arrival. For those hotels that have social media sites, which the concierge does not update, the most common department that was mentioned as responsible for updating those sites was sales and marketing (39\%) followed by PR (37\%). Other departments that are responsible included an outside company (7\%), corporate offices (4\%), IT (2\%), revenue management (2\%), owners (2\%), various departments (2\%), and unknown (4\%).

Finally, almost all of the respondents (98\%) reported that they receive emails from a company outside of their own hotels with information about local restaurants, events, shows, and information as shown in Table 2.

Table 2

Profile of Hotel Applications

\begin{tabular}{lll}
\hline & Hotel applications profile & \\
\hline Company has an app & Frequency & Percent (\%) \\
\hline Yes & 77 & 47 \\
No & 87 & 53 \\
\hline Hotel has an app & Frequency & Percent (\%) \\
\hline Yes & 54 & 33 \\
No & 110 & 67 \\
\hline Hotel has a Facebook page & Frequency & Percent (\%) \\
\hline Yes & 126 & 77 \\
No & 38 & 23 \\
\hline Hotel has a Twitter account & Frequency & Percent (\%) \\
\hline Yes & 102 & 62 \\
No & 62 & 38 \\
\hline Hotel has its own blog & Frequency & Percent (\%) \\
\hline Yes & 47 & 29 \\
No & 117 & 71 \\
\hline Update a hotel's social media accounts & Frequency & Percent (\%) \\
\hline Yes & 18 & 11 \\
No & 146 & 89 \\
\hline Receive emails re: local info from outside companies & Frequency & Percent (\%) \\
\hline Yes & 161 & 98 \\
No & 3 & 2 \\
\hline
\end{tabular}

\section{Perceptions of Concierges}

Part two of the survey dealt with the perceptions of the concierges related to their level of agreement with items regarding their position, guest requests, and technology. The means of the responses are presented below in Table 3. 
Table 3

Guest Request and Technology Questions

\begin{tabular}{|c|c|}
\hline Guest request & Mean response \\
\hline I receive more email from guests prior to their stay requesting help than before & 4.01 \\
\hline Guests want to know about the trendiest places more than before & 3.95 \\
\hline Guests want more personal recommendations than before & 3.85 \\
\hline Guests have done research on their requests prior to interacting & 3.71 \\
\hline Guests want me to confirm more reservations (airline, restaurant, and show) than before & 3.61 \\
\hline Guests make more demanding requests than they used to & 3.60 \\
\hline Guests use concierge services for different requests than they used to & 3.58 \\
\hline Guest requests are more time-consuming than previously & 3.41 \\
\hline \multicolumn{2}{|l|}{ Concierge tools and technology } \\
\hline I have the training I need to do my job & 4.51 \\
\hline I have the tools I need to do my job & 4.21 \\
\hline I have the technology I need to do my job & 4.06 \\
\hline My hotel has implemented new technology to help me serve my guests & 3.75 \\
\hline \multicolumn{2}{|l|}{ Guest technology use } \\
\hline Guests use their smart phones (i.e., iPhones, Blackberries, etc.) concierge services & 3.07 \\
\hline Guests use their laptops more than concierge services & 3.00 \\
\hline \multicolumn{2}{|l|}{ Internet as a tool } \\
\hline I can better serve my guests today because of the information available on the Internet & 4.64 \\
\hline The Internet is the strongest tool that I have to do my job & 4.02 \\
\hline \multicolumn{2}{|l|}{ Effort of concierge } \\
\hline I use my own personal connections to meet guest requests more than before & 3.91 \\
\hline I have to do more myself than before due to a reduction in staffing & 3.69 \\
\hline We have the proper staffing at the concierge desk to serve guests & 3.15 \\
\hline I use my personal smart phone a great deal to meet guest requests & 2.47 \\
\hline
\end{tabular}

The final part of the survey solicited open-ended comments from the concierges regarding any of the topics addressed in this research. Of the 164 usable responses, 49 provided comments for a response rate of 33\%. These comments were then coded and analyzed to determine common themes: concierge position, guest requests, guests conducting their own research, technology, and the Internet. These themes are further explored below.

\section{Concierge Position}

The following are some of the responses about the concierge position in terms of skills that respondents felt were necessary:

Personal knowledge, strong ethics, willingness to keep up with the newest local information, and desire to help guests is of major importance.

What a seasoned/experienced concierge provides guests with is the ability to size up the guests and tailor their responses and recommendations better. The guest benefits with a better choice and the concierge benefits by spending less time questioning the guests about their likes and dislikes.

Hotels need to recognize the importance of a concierge and what they really do, other than just making normal reservations.

The concierge is in a unique position to know the latest information in their region due to connections and interactions with vendors in that region. It is the only position in the hotel able to make "something out of nothing" and make the guest stay truly unique. 


\section{Guest Requests}

Comments about guest requests ranged from expectations of guests to the types of guests. Most concierges also felt that despite technology, guests still seem to want a personal touch:

Although technology is a great tool, I still strongly believe that it is the personal connections that I maintain with my colleagues and business partners that make me successful at my job. Guests come to my hotel for the "personal touch" that I and my staff provide. Internet information can be tainted and misrepresented. My recommendations are based on my solid relationships with my vendors and I take personal responsibility for those recommendations. The bottom line is that "I" will make it right. Can we say the same for Internet recommendations?

Technology has advanced in such way that people would be able to do things by themselves, but hotel guests at luxury properties are still accustomed to a certain level of service and prefer to be assisted by a person they can rely on. Technology will never exceed the level of service provided by the human resource, especially when the human resource sincerely cares to assist guests with their needs. Computers don’t have personal skills.

There is nothing like the personal assistance of a concierge to a hotel guest, regardless how advanced technology has become. Face to face, person to person is priceless. Anyone can use the Internet for their needs; however, when coming to a concierge for advice on my personal experiences, restaurants, shows, museums, etc., this is priceless.

Today, people want feedback about places that they have seen online but want to talk to a real person that has been there. People still like to interact with a person. Technology gets us there faster but always nicer to connect to a real human being.

I find that people like the personal contact that is given by the concierge. Also going above and beyond to anticipate guests' needs is always an art and will always be a top priority in the services we provide.

The 20-30 age group heavily depends upon their smart phones \& apps such as "Yelp" and then asks us for confirmation that their choices are good ones. The 60-70 age group still prefers the human touch and doesn't seem to utilize the Internet as much.

Guests have less patience and expect more information immediately. They plan less and do not want to pay for services that are beyond our control. Their demands have become outrageous, such as expecting the concierge to "open" a “closed" airport.

Most of my guests don't care about the personal recommendations we have to offer, they are looking for the “cheapest” places to go. Wal-Mart shoppers and Red Lobster diners are now the new clientele, and it's sad to see. They don’t care about quality, just quantity.

\section{Guests Conducting Own Research}

One of the areas that generated many comments related to guests conducting their own research prior to their hotel stay.

One concierge stated:

As a concierge who has worked "before" the Internet was invented, the traveling public still uses the concierge as much, or if not more than before the Internet, but what they are asking for is different. Prior to the Internet, we were used as "the source" for information. After the Internet, we are still used as an information source - just not "the source" for information. Today, we are asked to "confirm” facts that they (guests) might read about online, or we are asked about our opinion on a topic and then they will let us know that they read about it online.

Because of the nature of our hotel (boutique \& 4-star), our guests have always done research prior to arrival. The nature of how they do the research has changed, but not the dependability of the strong human to human connection that concierges have with vendors. 
Our guests watch the food channels and will request the trendiest places based on the information they have received from TV. They also come with their GPS so as you speak, they are busy checking your information on their phones or iPads.

Our guests range in age from young families to older couples and most are affluent and very travel savvy. It is no surprise that the younger guests are more drawn to advances in technology. They are more likely to do research online, book reservations online, or use a GPS instead of asking us for directions.

Guests do make a lot of their own plans although some still do show up at the hotel and want the concierge desk to "fill their time" without attempting any research of their own before arrival.

Guests are using technology more than before, but they are testing the concierge on their take on what they find on their own.

Though technology has had its advantages, people by nature want confirmation about what they have heard or read about from someone who is deemed an expert on the subject or is within the realm of experiencing it. Anyone or any company can design and place a website on the Internet. It does not necessarily mean it is one of validity.

Many guests get recommendations from the concierge and then book on open table or call the establishment themselves from notepad, smart phone, etc.. Guests are using more technology to find how restaurants are rated. They like to hear our recommendations and then check on the web to see if public or professional opinions concur with concierge recommendations.

\section{Technology and the Internet}

The comments on technology ranged from the Internet itself to concierge systems to mobile devices. One respondent noted that a concierge system has been very beneficial:

The addition of concierge system software has been a huge advantage in recent years.

I wish my hotel would buy GoConcierge or any other concierge system to help me do my job. It is old-fashioned to rely on talking to the guest and finding out more about their needs and wishes. They ask us for information then say they will check out our recommendations on the Internet and then make their own reservations.

Navigation devices have given guests the sense that they simply need the address of a destination and they will be shown the best way to reach it. Navigation devices do not factor in traffic conditions, construction zones, special events, etc..

The strongest concierge tools are our experiences and our contacts; however, I can’t imagine being a concierge before the Internet, and I would not want to be a concierge without it! I think hotels need to incorporate the right technology into guest services (and not those cheesy kiosks with outdated information).

The Internet has definitely made researching guest requests easier and less time-consuming, although there are now more requests to research than before.

The theme that generated the most comments in the area of technology was the use of smart phones and tablets. Some of the comments about smart phones and tablets were about their impact on the concierge. For example, one stated:

I truly feel that the iPhone, with all the apps for travel, dining, etc., will put concierges out of business due to everything being in the palm of the guests' hands. Mobile devices are much faster than my work computers.

I feel that our desk has done a great job keeping up with technology available to serve our guests. We have had iPads for almost a year. We use them to show menus and pictures of our restaurants, look up information to share with guests, mapping, and movie times and trailers.

While smart phones and the Internet are excellent tools for both the guests and concierges to use, they can't make up for personal experiences and contacts. The smart phone won't be able to describe in detail how the ambience feels.

At first, I thought the iPad would destroy my career but, in my hotel, luxury guests demand a personal touch. 


\section{Discussion}

The purpose of the study was to explore perceptions of hotel concierges on how their roles and jobs have changed. Five major factors related to concierge perceptions evolved. They were guest requests, concierge tools and technology, guest technology use, Internet as a tool, and effort of the concierge. The guest request factor, included items such as guests have more demanding requests, requests are more time-consuming, and guests want more personal recommendations. A recent survey found that $64 \%$ of guests said that they use social media to make plans while traveling (De Lollis, 2010). However, despite doing their own research, guests still seem to want to know about the trendiest places to go and feel that concierges are the best ones to direct them as pointed out by one veteran concierge manager in the New York City. In addition, participants in the survey confirmed this as the mean score for this question was 3.95 and the mean score on guests wanting personal recommendations was 3.85. Factor five, effort of the concierge, contained items related to concierges having to do more themselves and using their own personal connections to serve the guests. Hotels need to ensure that concierges not only have the proper tools to access current information, but that they are given training in terms of the "hot spots" in the hotel's location. Hotels must also provide proper training to the concierges about how to use the Internet in terms of "mining" it for information if the concierge does not know how to do so. This will continue to be especially important as guests come to the concierge desk having done prior research.

Concierges seemed to feel that guests are conducting more research on their own. The high score on this question indicated that concierges perceive guests to be doing their own research before interacting with the concierge. In addition, many concierges commented on this topic in their open-ended responses. One concierge summed it up by stating that:

As a concierge who has worked "before" the Internet was invented, the traveling public still uses the concierge as much, or if not more than before the internet, but what they are asking for is different. Prior to the Internet we were used as "the source" for information. After the Internet, we are still used as an information source — just not "the main source" for information. Today, we are asked to "confirm” facts that they (guests) might read about online, or we are asked about our opinion on a topic and then they will let us know that they have read about it online.

Therefore, hotel management should work with the IT departments to ensure that concierges have the most up-to-date technology and applications to be able to serve the guests. For example, the online concierge tool called GoConcierge, which helps concierges to provide and manage information given to guests (Arnaldo, 2011). The IT departments should also get recommendations from the concierge employees on what systems or technical functions they need.

In terms of a hotel's use of technology, there is a give-and-take relationship between hotels implementing technology and not wanting to lose personalized service. Clearly, many hotels are starting to utilize more self-service types of technology from in-room ordering systems to virtual concierges. However, many also noted that they did not want to lose the personalized service aspect that makes hospitality what it is. Concierges also felt that they need to maintain face-to-face interaction in order to do their jobs. As Arnaldo (2011) discovered, one concierge said that the computer sometimes takes him away from personal interaction with the guests. In another study, one manager spoke about how guests want the interaction in order to have a great experience (Stoessel, 2010). Despite not wanting to lose guest interaction, concierges agree that the Internet is a vital tool for their job. This is reflected in the mean score of 4.64 for the question about being able to better serve guests due to the Internet and the mean score of 4.02 for the question about the Internet as the strongest 
tool that a concierge has to do the job. While some concierges are probably concerned about the internet, apps, smart phones, and laptops taking away their jobs, one concierge commented that:

While smart phones and the Internet are excellent tools for both the guests and concierges to use, they can't make up for personal experiences and contacts. The smart phone won't be able to describe in detail the ambience of a place.

This demonstrates that while guests may be using technology to access information, the information they find cannot replace the concierge's personal feelings about it and therefore, the need for personal interaction to enhance the guests' experience is necessary.

\section{Conclusions and Implications}

There are some clear-cut conclusions that can be drawn. Like many industries, the hotel industry has been taking advantage of technology to gain efficiencies and provide additional types of service (Bilgihan et al., 2011). While the implementation of such technology has improved hotel efficiencies, it does not necessarily detract from the personal nature of a guest's experience. Therefore, hotel management cannot overlook the guests' need for personalized service, so managers are cautioned against implementing too much guest SST, which can lessen the guests' overall experience. If the hotel is going to implement new guest technology, management should ensure that guests can select between whether they want personalized service or are happy with self-service. Providing both options is valuable, because it does not force guests to use technology that they may feel uncomfortable using (Bitner et al., 2000). Therefore, by providing options, guests can "select the service delivery system that best meets their needs for each interaction” (Meuter, Ostrom, Bitner, \& Roundtree, 2003, p. 905). Moreover, managers need to be aware that guest-related technologies do not always improve hotel performance and can even decrease productivity (Ham et al., 2005). While some guests may like hotel technology, managers should not assume that performance will be improved with technology implementation (Ham et al., 2005).

Hotel managers may be better advised to focus on technology that can enhance the concierges' jobs in order for them to provide excellent guest services. For example, Intercontinental has implemented the use of iPads by concierges. One of the respondents indicated that this was the best piece of technology that his hotel had implemented in several years:

We use them to show menus and pictures of our restaurants, look up information to share with guests, mapping, and movie times and trailers. When not in use, they are on our desk in photo frame mode showing pictures of our restaurants and activities.

Another example is the GoConcierge web-based system that allows concierges to manage guest requests through maintaining guest profiles, making dining reservations, searching for information about restaurants and attractions, creating and managing employee tasks, and more. Concierges are the linchpin between the hotel and the guests and are vital to the guest experience. Therefore, managers may be better off investing in technology for the concierge as opposed to technology for the guests. Maintaining a "high-touch, low-tech" environment may further allow a hotel to differentiate (Craig, 2010).

It is important for researchers to understand the role of technology in service encounters given the increase in technology applications (Meuter et al., 2003). Many studies have been done on company use of technology from the customers' perspective, but there are fewer from the employees' perspective and even less within the hotel context. In addition, understanding the impact of these technology applications from the perspective of 
employees is critical to both academia and industry. Adding to existing literature on technology in service encounters, this study explored how the role of the concierge has been impacted due to advances in technology from the perspective of the concierge and outlined implications for hotel managers. The opinions of hotel concierges are important to consider in planning future service options for guests.

\section{Limitations and Future Research}

While the study is representative of the concierges who participated in the survey, the possibility exists for differences based on location of the hotel, type of hotel, type of guests who usually stay at the hotel, and other variables. The study is also limited by self-reporting of the concierges regarding changes in the volume of guest requests and types of guest requests. Future research should evaluate the changes in guest requests due to technological applications and how these have affected hotel service delivery. The study was limited to those concierges who are in four- and five-star hotels, because the inherent nature of the concierge position is that it is found in these types of higher-level service hotels. Similar duties may be performed in limited service hotels, so future research should also explore the role of individuals who do not hold the title of concierge but offer similar types of services. In addition, research could be conducted on general manager attitudes about such services. Future research should also assess the roles of both the IT and concierge departments in technology implementation.

\section{References}

Arnaldo, M. (2011). Concierge (Cone-see-air-j). In M. O’Fallon, \& D. Rutherford (Eds.), Hotel management and operations (pp. 144-150). Hoboken, N.J.: John Wiley \& Sons, Inc..

Beatson, A., Coote, L., \& Rudd, J. (2006). Determining customer satisfaction and commitment through self-service technology and personal service. Journal of Marketing Management, 22(7), 853-882.

Bilgihan, A., Okumus, F., Nusair, K., \& Kwun, D. (2011). Information technology applications and competitive advantage in hotel companies. Journal of Hospitality and Tourism Technology, 2(2), 139-154.

Bitner, M. J., Brown, S. W., \& Meuter, M. L. (2000). Technology infusion in service encounters. Journal of the Academy of Marketing Science, 28(1), 138-149.

Craig, D. (2010, August 31). Are concierges obsolete? Retrieved from http://www.blog.danieledwardcraig.com/2010/07/is-role-of-hotel-concierge-going.html

Crowell, C. (2010). Technology drives on-property spend. Retrieved from Hospitality and Tourism Complete Database. Hotel and Motel Management, 225(2).

De Lollis, B. (2010, November 17). Survey: 60\% use social media to "call” home when traveling instead of phone, e-mail. Retrieved from http://travel.usatoday.com/hotels/post/2010/11/sheraton-survey-social-media-beats-phone-email-/131575/1

Ham, S., Kim, W., \& Jeong, S. (2005). Effect of information technology on performance in upscale hotels. International Journal of Hospitality Management, 24(2), 281-294.

Hill, C. (2013, October 20). Hotels hire specialists to cure guests' hangovers. Wall Street Journal.

InSites Consulting. (2012, June 20). Survey shows 80 percent of companies use Facebook. Retrieved from http://www.vendingmarketwatch.com/news/10732362/survey-shows-80-percent-of-companies-use-facebook

Joseph, M., McClure, C., \& Joseph, J. (1999). Service quality in the banking sector: The impact of technology in service delivery. International Journal of Bank Marketing, 19(4), 182-193.

Kasavana, M., Nusair, K., \& Teodosic, K. (2010). Online social networking: Redefining the human web. Journal of Hospitality and Tourism Technology, 1(1), 68-82.

Kirby, A. (2009). Hotels get app happy. Hotels, 43(9A), 42-43.

Levere, J. (2011, June 27). The virtual hotel concierge. New York Times.

Lombardi, R. (2010). Moving targets. Hotelier, 22(2), 51-53.

Madden, K. (2010). What it’s like to be a hotel concierge? Retrieved from http://www.cnn.com/2010/living/10/11/cb.hotel.concierge

McMullen, S. (2006). Online concierge services help build loyalty. Hotel and Motel Management, 221(14), 22. 
Meuter, M. L., Ostrom, A. L., Bitner, M. J., \& Roundtree, R. (2003). The influence of technology anxiety on consumer use and experiences with self-service technologies. Journal of Business Research, 56(11), 899-906.

Meuter, M. L., Ostrom, A. L., Roundtree, R., \& Bitner, M. J. (2000). Self-service technologies: Understanding customer satisfaction with technology-based service encounters. Journal of Marketing, 64(3), 50-64.

Nayer, M. (2011). Facebook: The new face of the hotel concierge. Hotel, Travel, and Hospitality News.

Noel, J. (2012). Technology is changing service. Hotel Business Review. Retrieved from http://hotelexecutive.com/business_review/3276/mobile-concierge-how-technology-is-changing-service

Parasuraman, A., Zeithaml, V., \& Berry, L. (1985). A conceptual model of service quality and its implications for future research. Journal of Marketing, 49, 41-50.

Rogers, D. (2009). Most outrageous hotel concierge requests. Travel and Leisure.

Schrier, T., Erdem, M., \& Brewer, P. (2010). Merging task-technology fit and technology acceptance models to assess guest empowerment technology usage in hotels. Journal of Hospitality and Tourism Technology, 1(3), 201-217.

Stiel, H. (2010). Philosophy. Retrieved from http://www.thankyouverymuchinc.com

Stoessel, E. (2010). More than a concierge. Lodging Hospitality, 66(14), 35-40.

Tanguy, J. (2013). What qualities to look for when hiring a hotel concierge. Retrieved from http://hotelexecutive.com/business_review/3291/what\%20qualities-to-look-for-when-hiring-a-concierge

Yeh, R., Leong, J., Blecher, L., \& Lai, H. (2005). Analysis of hoteliers' e-commerce and information technology applications: Business travelers' perceptions and needs. International Journal of Hospitality and Tourism Administration, 6(2), 29-62.

You, T. (2012). Are hotel concierges becoming obsolete? Retrieved from http://travel.cnn.com/explorations/life/are-hotel-concierges-becoming-obsolete-407573 